\title{
Transcript and proteomic analysis of developing white lupin (Lupinus albus L.) roots
}

\author{
Li Tian* ${ }^{*} 1,2$, Gregory J Peel ${ }^{\dagger 1}$, Zhentian Lei ${ }^{1}$, Naveed Aziz ${ }^{1,3}$, Xinbin Dai ${ }^{1}$, \\ Ji He ${ }^{1}$, Bonnie Watson ${ }^{1}$, Patrick X Zhao ${ }^{1}$, Lloyd W Sumner ${ }^{1}$ and \\ Richard A Dixon ${ }^{1}$
}

Address: ${ }^{1}$ Plant Biology Division, Samuel Roberts Noble Foundation, Ardmore, OK 73401, USA, ${ }^{2}$ Department of Plant Sciences, University of California, Davis, Davis, CA 95616, USA and ${ }^{3}$ CNAP, Department of Biology, University of York, York, YO 10 5YW, UK

Email: Li Tian* - ltian@ucdavis.edu; Gregory J Peel - gipeel@noble.org; Zhentian Lei - zlei@noble.org; Naveed Aziz - na9@york.ac.uk; Xinbin Dai -xdai@noble.org; Ji He - jhe@noble.org; Bonnie Watson - bowatson@noble.org; Patrick X Zhao - pzhao@noble.org; Lloyd W Sumner - lwsumner@noble.org; Richard A Dixon - radixon@noble.org

* Corresponding author †Equal contributors

Published: 5 January 2009

BMC Plant Biology 2009, 9:1 doi:10.1 186/1471-2229-9-1
Received: 16 September 2008

Accepted: 5 January 2009

This article is available from: http://www.biomedcentral.com/I47I-2229/9/I

(c) 2009 Tian et al; licensee BioMed Central Ltd.

This is an Open Access article distributed under the terms of the Creative Commons Attribution License (http://creativecommons.org/licenses/by/2.0), which permits unrestricted use, distribution, and reproduction in any medium, provided the original work is properly cited.

\begin{abstract}
Background: White lupin (Lupinus albus L.) roots efficiently take up and accumulate (heavy) metals, adapt to phosphate deficiency by forming cluster roots, and secrete antimicrobial prenylated isoflavones during development. Genomic and proteomic approaches were applied to identify candidate genes and proteins involved in antimicrobial defense and (heavy) metal uptake and translocation.

Results: A cDNA library was constructed from roots of white lupin seedlings. Eight thousand clones were randomly sequenced and assembled into 2,455 unigenes, which were annotated based on homologous matches in the NCBInr protein database. A reference map of developing white lupin root proteins was established through 2-D gel electrophoresis and peptide mass fingerprinting. High quality peptide mass spectra were obtained for 170 proteins. Microsomal membrane proteins were separated by I-D gel electrophoresis and identified by LC-MS/MS. A total of 74 proteins were putatively identified by the peptide mass fingerprinting and the LC-MS/MS methods. Genomic and proteomic analyses identified candidate genes and proteins encoding metal binding and/or transport proteins, transcription factors, $A B C$ transporters and phenylpropanoid biosynthetic enzymes.

Conclusion: The combined EST and protein datasets will facilitate the understanding of white lupin's response to biotic and abiotic stresses and its utility for phytoremediation. The root ESTs provided 82 perfect simple sequence repeat (SSR) markers with potential utility in breeding white lupin for enhanced agronomic traits.
\end{abstract}

\section{Background}

Nitrogen and phosphate are essential plant mineral nutrients and limiting factors for plant growth under stress.
Due to poor soil conditions and limited nutrient uptake capacities, most crop plants require fertilizer applications to prevent nitrogen and phosphate deficiency; fertilizer 
use is expensive and causes serious long term ecological problems. It is therefore desirable to improve the efficiency of plant mineral nutrient uptake from soil. White lupin fixes nitrogen efficiently through its symbiotic association with Bradyrhizobia, and adapts to phosphate deficiency by developing cluster roots and secreting organic acids to solubilize inorganic phosphate in the soil [1]. In recent years, efforts have been directed toward understanding the mechanisms of nutrient uptake in white lupin for broader applications in crop improvement.

In addition to poor soil nutrient content, the use of lands for farming is also limited by metal contamination. There has been emerging interest in the use of white lupin for phytoremediation. White lupin can accumulate $\mathrm{Zn}, \mathrm{Mn}$, and $\mathrm{Al}$, and heavy metals such as $\mathrm{Cd}, \mathrm{Pb}, \mathrm{Hg}$ and $\mathrm{Cr}$, at high concentrations without affecting plant growth [2-4]. Although (heavy) metal uptake from soil and transport from root to shoot have been demonstrated in white lupin, little is known about the genes and enzymes responsible for (heavy) metal uptake and translocation within white lupin plants.

A wide variety of isoflavones are synthesized and exuded during development of white lupin roots. These include genistein and 2'-hydroxy genistein, and their 6-, 8-, and 3'monoprenylated, 6, 3'-diprenylated, and 7-O-glucosyl derivatives. Isoflavones are well known for their roles in plant disease responses [5]. In contrast to the phenylpropanoid phytoalexins that accumulate upon pathogen attack, prenylated isoflavones accumulate constitutively in white lupin and are designated as phytoanticipins [6]. Prenylation significantly increases the activity of the core compounds, and prenyltransferase genes therefore have potential applications in plant disease resistance and human health [7]. Biochemical studies in white lupin have shown that more than one membrane-bound prenyltransferase is responsible for the prenyl transfer reactions, which occur at different positions of the isoflavone ring structure. Although the reactions leading to genistein and 2'-hydroxygenistein biosynthesis have been elucidated in several plant systems, the molecular identities of the isoflavone prenyltransferases are still unknown. Recently, a flavonoid specific prenyltransferase, naringenin 8-prenyltransferase (SfN8DT-1), was cloned and characterized from Sophora flavescens [8]. SfN8DT-1 is membrane-bound and is related evolutionarily to the previously identified plant aromatic prenyltransferases involved in tocopherol and plastoquinone biosynthesis [8].

The adenosine triphosphate-binding cassette $(\mathrm{ABC})$ family transporters mediate transport of a wide variety of molecules across biological membranes and play critical roles in plant growth and development. Plant ABC transporters can be classified into 13 subfamilies based on their size, orientation, and the transmembrane and linker domains of the protein [9]. Transport of glycoside- and glutathione-conjugated phenylpropanoid compounds has been reported to be mediated by members of the multidrug resistance associated protein (MRP) subfamily of $A B C$ transporters [10,11]. Recently, the involvement of an $A B C$ transporter in the secretion of genistein aglycone from soybean roots was reported [12]. However, the mode of transportation of prenylated isoflavonoids remains unclear.

White lupin is an agronomically important crop because the grains are high in protein and fiber and low in starch and oil [13]. Understanding white lupin root development and metabolism will facilitate breeding for favorable agronomic traits. Furthermore, understanding the mechanism of (heavy) metal uptake and transport, and antimicrobial isoflavone synthesis and exudation in white lupin roots will have broad applications for understanding and engineering efficient soil nutrient uptake, disease resistance and phytoremediation properties in other plants. However, previous studies on white lupin root transcripts have focused on the gene expression patterns in cluster root development and in response to phosphate deficiency (in particular, the phosphate transporters) [1417]. Most of the white lupin nucleotide sequences currently available in the GenBank database were obtained from two cDNA libraries that were constructed from cluster roots of phosphate-deficient white lupin plants [17]. White lupin still lacks extensive genomics resources. Furthermore, the steady state transcript levels in a specific organ such as roots may not directly reflect the corresponding protein population.

We here describe an EST database and a protein reference map from developing white lupin roots to aid identification of candidate genes relevant to antimicrobial defense and phytoremediation. The EST collection also revealed a number of simple sequence repeat (SSR) markers of potential utility for lupin breeding.

\section{Methods \\ Plant material and RNA extraction}

White lupin seeds (Lupinus albus v Lupro 2085) were scarified, germinated in a coarse sand and turface mixture and grown under greenhouse conditions (with a $16 \mathrm{~h}$ day, $8 \mathrm{~h}$ night cycle). Seedling roots were harvested at 5, 10, 15 and 20 days post-emergence, immediately frozen in liquid nitrogen and stored at $-80^{\circ} \mathrm{C}$ prior to analysis. Total RNA was extracted from the root tissue using TRI reagent (Molecular Research Center, Cincinnati, OH). Equal amounts of RNA sample from each time point were pooled and the combined total RNA was used for cDNA library construction. Roots for protein analysis were 
grown under the same greenhouse conditions, and harvested at 17 days post-emergence. Normal roots (not cluster roots) were used for RNA extractions and protein analysis.

\section{cDNA library construction, EST sequencing and analysis} A developing white lupin root cDNA library was prepared from total RNA using the Creator Smart cDNA library construction kit (BD Bioscience, Palo Alto, CA) following the manufacturer's instructions, and was transformed into $E$. coli. Eight thousand bacterial clones were randomly picked and used for inoculation of liquid culture. Plasmid DNA was purified from the overnight liquid culture and sequenced with the M13 forward primer. After removing short reads (less than $100 \mathrm{bp}$ ) and vector sequences, the remaining ESTs were clustered and assembled with the TGICL program http://compbio.dfci.harvard.edu/tgi/soft ware/ using its default parameter settings (at least $40 \mathrm{bp}$ overlap with at least $94 \%$ identities). The unigenes (contigs and singletons) were used for performing homology searches with an automatic BLAST search and data mining tool [18]. Six-frame translations of the unigene sequences were searched against the NCBI protein database using the BLASTX algorithm. Unigene sequences with $E$ values greater than 0.1 were classified as no hit. For gene ontology (GO) analysis, the lupin root unigenes were searched against the Arabidopsis thaliana database http://www.ara bidopsis.org and the corresponding Arabidopsis Gene Index (AGI) numbers were obtained. AGI numbers of the best matches were used for searching the Arabidopsis GO annotations http://www.arabidopsis.org/tools/bulk/go/ index.jsp and were divided into the three major classes that are common to all eukaryotes: biological process, cellular component and molecular function. The functional classification was also manually inspected and minor adjustments were made to ensure appropriate assignment of GO annotations.

\section{Protein extraction and gel electrophoresis}

Roots of $17 \mathrm{~d}$ old white lupin seedlings were harvested and frozen in liquid nitrogen. The frozen root tissue was ground into a fine powder using a cryogenic grinder (Fisher Scientific, Hampton, NH). Two volumes of extraction buffer (100 mM potassium phosphate $\mathrm{pH} 7.5,400$ $\mathrm{mM}$ sucrose, $28 \mu \mathrm{M} \beta$-mercaptoethanol) and 5\% polyvinylpolypyrrolidone (PVPP) were added to the ground powder. The root tissue was homogenized in the extraction buffer with a polytron twice for $30 \mathrm{~s}$ each, and then centrifuged at 8,000 $\mathrm{g}$ for $15 \mathrm{~min}$. The supernatant was filtered through glass wool to remove the cell debris. Protein concentration was determined by the Bradford assay [19]. A portion of the supernatant was brought to a final concentration of (w/v) $12.5 \%$ trichloroacetic acid (TCA) with TCA/acetone solution and protein was collected by centrifugation. The protein pellet was then washed three times with $80 \%$ acetone containing $0.05 \% \quad \beta$-mercaptoethanol, air dried, resuspended in resolubilization solution ( $8 \mathrm{M}$ urea, 4\% CHAPS, $20 \mathrm{mM}$ DTT, 0.2\% biolytes), and analyzed by 2-D gel electrophoresis. The remainder of the supernatant was centrifuged at $140,000 \mathrm{~g}$ for $60 \mathrm{~min}$. The microsomal pellet was washed twice with extraction buffer, resuspended in SDS-PAGE sample loading buffer, and analyzed by 1-D gel electrophoresis.

One thousand two hundred $\mu \mathrm{g}$ total proteins from developing white lupin roots were separated by 2-D gel electrophoresis as previously described [16]. One hundred $\mu \mathrm{g}$ microsomal proteins were separated in a pre-cast SDSPAGE gradient gel (4-15\%) and stained with Coomassie Brilliant Blue R250 (BioRad Laboratories, Hercules, CA). Gel images were captured by a BioRad Fluor S MultiImager (BioRad Laboratories, Hercules, CA).

\section{Protein digestion and identification}

Protein spots from the Coomassie stained 2-D gel were manually excised, destained and in-gel digested with trypsin as previously described [20]. Peptide fragments from digested proteins were mixed $(1: 1, \mathrm{v} / \mathrm{v})$ with matrix ( $\alpha$-cyano-4-hydroxycinnamic acid, $10 \mathrm{mg} / \mathrm{ml}$ ), spotted and analyzed by matrix-assisted laser desorption/ionization-time of flight mass spectrometry (MALDI-TOF MS). Mass spectra were acquired using a PerSeptive Biosystems Voyager DE STR (Applied Biosystems, Framingham, MA) in the positive ion reflector mode with a mass range from $900 \mathrm{Da}$ to 4,000 Da. One hundred shots were triggered for each spectrum and four independent spectra were collected and averaged. Protein identification through peptide mass fingerprinting (PMF) was performed by querying the peptide masses against both NCBInr protein database and a custom legume database developed by Dr. Lloyd Sumner's group and the Noble Foundation bioinformatics team, using Mascot that employs a probabilitybased scoring system (version 2.2, Matrix Science, UK). The custom legume database contains protein sequences imported from the NCBInr protein database for a range of legumes, including Medicago sativa, M. truncatula, Lotus japonicus, Glycine max, Pisum sativum, Phaseolus vulguris, Lupinus albus and L. luteus (Lei et al. unpublished). In addition, tentative contig (TC) sequences from M. truncatula, L. japonicus and G. max, and six-frame translations of developing white lupin root unigenes from the EST analysis were added to the custom legume database. For peptide matching, a maximum of one missed cleavage was allowed and a minimum of four peptide matches was required. The maximum molecular weight discrepancy was set at $100 \mathrm{ppm}$.

For microsomal proteins, sixteen $5 \mathrm{~mm}$ slices were excised from the 1-D protein gel and transferred to microcentrifuge tubes. After in gel trypsin digestion, peptides were 
extracted, separated and analyzed by LC-MS/MS. The quadruple-time of flight mass spectrometer QSTAR (Applied Biosystems, Forster City, CA) was coupled to a nano-scale high performance liquid chromatography (HPLC) system (Dionex, San Francisco, CA), which includes an autosampler (Famos), a precolumn switching device (Switchos) and an HPLC pump system (Ultimate), and allows for sensitive detection on small amounts of peptide samples. The HPLC gradient for peptide separation and the parameters for MS data acquisition and analysis were described previously [21]. Peptide identification was performed using the Mascot software (Matrix Science, Boston, MA). Both NCBInr protein database and the custom legume database were queried using the acquired mass spectral data, with a mass tolerance of 100 ppm. Proteins with a molecular weight search score greater than 30 and a minimum two matched peptides are reported.

\section{Mining of SSRs}

SSR identification, PCR primer design and in silico amplification from the designed primers were performed and hosted by an in-house developed web server, PhpSSRMiner, which is available at http://bioinfo.noble.org/ phpssrminer/index.php. PhpSSRMiner provides a userfriendly interface which integrates its back-end pipeline to streamline the process of perfect SSR identification by SSRIT [22], imperfect SSR identification by Sputnik http:/ Labajian.net/sputnik[23], PCR primer design using Primer3 [24] and in silico amplification of the designed primers via IsPCR [25]. The 2,455 white lupin unigenes were analyzed using the PhpSSRMiner web server to identify perfect SSR candidates with SSR length equal or greater than $20 \mathrm{nt}$. The analysis results can be exported from PhpSSRMiner as tab-delimited text files with separate columns for the positions and sequences of the forward and reverse primers, type of SSR repeat (perfect vs. imperfect), SSR motif and length.

\section{Results and discussion Generation and functional annotation of developing white lupin root ESTs}

A total of 8,000 clones were randomly picked and sequenced from their 5 ' ends. After removing low quality, short reads and vector sequences, the remaining ESTs $(5,150)$ were assembled into 2,455 unigenes, which included 540 contigs and 1,915 singletons. As of April 2008, 112 protein sequences and 2,412 nucleotide sequences from white lupin were present in the NCBI database, many from plants subjected to phosphate deficiency. The deposition of the developing white lupin root ESTs (GenBank accession numbers FG089554 FG094703) has therefore doubled the amount of publicly available white lupin nucleotide sequences. In addition, 1544 (63\%) of the developing white lupin root unigenes do not have any hits when searched against the previously published white lupin nucleotide sequences (tBLASTx search with an $E$ value greater than or equal to $10^{-5}$ ), presenting new information on the white lupin genome (Additional File 1).

GO terms are commonly used to describe the functions of genes and gene products and to facilitate queries among genes from different organisms. A concise GO annotation requires combined computational and manual methods following a common standard that has been set by the Gene Ontology Consortium [26,27]. A detailed GO annotation system has been established for the fully sequenced Arabidopsis thaliana genome [28]. The white lupin root unigenes were functionally classified based on similarities with annotated genes in Arabidopsis. A total of 1,785 white lupin unigenes had significant hits ( $E$ value less than or equal to $10^{-4}$ ) with Arabidopsis genes. The relative frequency of white lupin root unigene hits in each GO category is presented in Figure 1. It should be noted that when the unigenes are described as unknown, they have unknown GO terms rather than representing genes encoding proteins with unknown functions.

The white lupin root unigenes cover a broad range of functional categories (Figure 1). Overall, the unclassified ("unknown" or "other") GO annotations accounted for over $40 \%$ of the total unigenes in each category. In the category of molecular function, $44 \%$ were classified as having unknown molecular functions, other enzyme activities, other binding and other molecular functions. In biological process, $60 \%$ of the unigenes were classified as other metabolic processes, other cellular processes, unknown biological processes and other biological processes. Under the category of cellular component, the four most frequent GO hits were other membranes, other intracellular components, unknown cellular components and other cytoplasmic components, accounting for a total of $63 \%$ in this category. In addition, although the white lupin ESTs were derived from root tissue, some unigenes showed sequence homology to Arabidopsis genes encoding chloroplast proteins, presumably due to certain conserved motifs that are shared between the sequences. Alternatively, it is possible that they are homologous sequences encoding chloroplast and leucoplast proteins, respectively. Overlapping annotations also existed among some of the subcategories.

Out of the top 20 most abundant unigenes from white lupin roots, 17 showed high similarity to genes encoding proteins from other leguminous plants, and 10 overlapped with the abundant unigenes in phosphate-deficient white lupin roots (Table 1) [17]. The most abundant unigene was a perfect match to the previously reported pathogenesis-related protein 10 from white lupin. LaPR10 was previously isolated and characterized from $10 \mathrm{~d}$ 


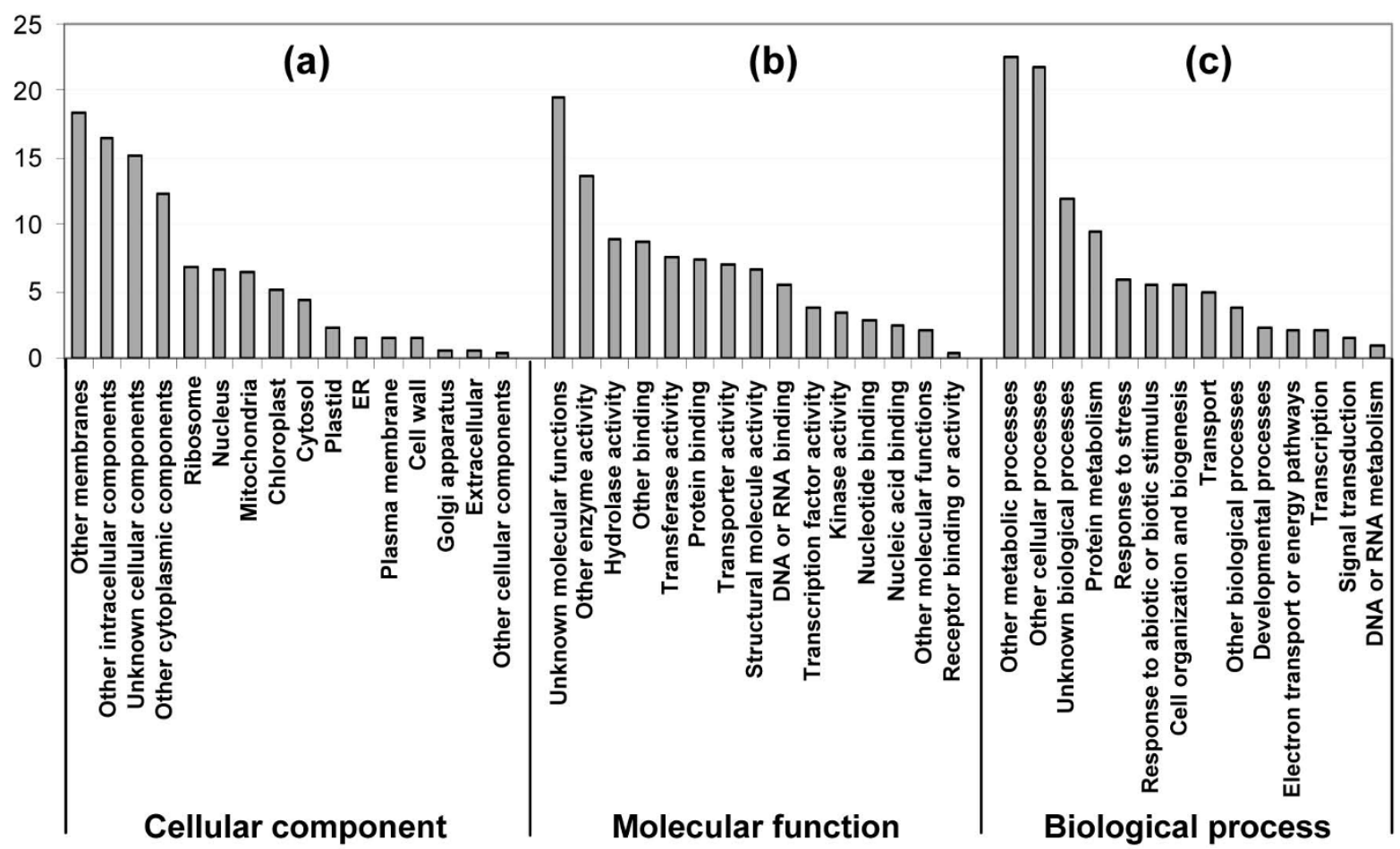

Figure I

Functional classification of the developing white lupin root unigene dataset. The unigene sequences were searched against the Arabidopsis database http://www.Arabidopsis.org and were functionally classified based on the GO annotations of their Arabidopsis homologs. The relative frequencies (\%) of GO hits (Y axis) for functional categories of a) cellular component, b) molecular function, and c) biological process are shown.

old healthy root tissues of white lupin [29]. It showed sequence similarity to pathogenesis related proteins from other plant species and exhibited ribonuclease activity. Although most pathogenesis related proteins are induced upon pathogen attack, LaPR-10 is constitutively expressed throughout root development. The expression of LaPR-10 indicates that, together with the constitutive secretion of prenylated isoflavones, white lupin roots contain a well established, pre-formed defense system. Interestingly, a unigene with homology to pathogenesis-related protein 1 has the most redundant ESTs in a CDNA library derived from roots of phosphate-deficient common bean (Phaseolus vulgaris) plants [30].

Table 1 also shows the presence of abundant unigenes associated with metal and water uptake functions. When the second most abundant unigene was searched against the NCBI protein database, no significant homologs were found. However, when the NCBI non-redundant EST database was searched using the tBLASTx method, the unigene showed significant but low homology to a Medicago sativa type 1 metallothionein (MET1) $(E=1 \mathrm{e}-12)$. Metallothioneins are cysteine-rich proteins that can bind metals and oxidant radicals. Another white lupin homolog of metallothionein contained 19 ESTs in the present collection (Table 1). Aquaporins facilitate water transport across membranes, and several unigenes homologous to aquaporins were abundantly represented in the white lupin root EST database (Table 1). Genes encoding metallothioneins and aquaporins are also among the most abundant transcripts in non-stressed poplar (Populus trichocarpa $\times$ deltoids) roots [31]. Thiamine (vitamin B1) is used as a co-enzyme for dehydration of $\alpha$-keto acids, such as in the reaction catalyzed by malate dehydrogenase, and is also a cofactor for pyruvate dehydrogenase. A unigene encoding a thiamin biosynthetic enzyme was the fourth most abundant unigene in the developing white lupin root cDNA library (Table 1 ).

\section{Isoflavonoid biosynthetic pathway genes are well represented in the EST database}

Consistent with the constitutive synthesis and secretion of isoflavone metabolites, genes encoding isoflavone biosynthetic enzymes were present in the white lupin root EST database. These included the general phenylpropanoid pathway genes encoding L-phenylalanine ammonialyase, chalcone synthase, chalcone isomerase (isoforms 2 and 4), and the isoflavonoid pathway specific genes 
Table I: The 20 most abundantly expressed unigenes in the developing white lupin root cDNA library.

\begin{tabular}{|c|c|c|c|c|}
\hline Unigene & \# ESTs & Top BLAST hit & $\begin{array}{c}\text { NCBI } \\
\text { Accession No. }\end{array}$ & $E$ value \\
\hline 0016 & 244 & Pathogenesis-related 10 (Lupinus albus) & BAB63949 & $5 e-84$ \\
\hline 0007 & 97 & No hit & & \\
\hline 0019 & 83 & Ripening related protein (Glycine max) & AAD50376 & $8 e-51$ \\
\hline 0021 & 30 & Thiamin biosynthetic enzyme (Glycine max) & BAA88228 & $2 e-154$ \\
\hline 0022 & 29 & MtN5 (Medicago truncatula) & CAA75593 & $5 e-23$ \\
\hline 0025 & 29 & Hypothetical protein (Medicago truncatula) & ABD32999 & 0.013 \\
\hline 0026 & 26 & Profucosidase (Pisum sativum) & CAA09607 & le-67 \\
\hline 0023 & 20 & Probable aquaporin TIP-type (MtAQPI) (Medicago truncatula) & Q9FYI4 & $1 e-116$ \\
\hline 0027 & 19 & No hit & & \\
\hline 0028 & 19 & Metallothionein-like protein (Arachis hypogaea) & AAO92264 & $4 e-23$ \\
\hline 0030 & 17 & Probable glutathione S-transferase (Glycine max) & P32II0 & $4 e-96$ \\
\hline 0031 & 16 & Hypothetical protein (Plantago major) & $\mathrm{CAH} 59408$ & $8 e-34$ \\
\hline 0035 & 15 & Auxin-repressed protein (Robinia pseudoacacia) & AAG33924 & $3 e-38$ \\
\hline 0038 & 14 & Aquaporin (Lupinus albus) & CAAII025 & le-158 \\
\hline 0041 & 12 & Calcium-binding EF-hand (Medicago truncatula) & ABE82233 & $5 e-41$ \\
\hline 0042 & 12 & Aquaporin 2 (Samanea saman) & AACI7529 & $5 e-149$ \\
\hline 0043 & 11 & Thaumatin-like protein PR-5b (Cicer arietinum) & CAA09228 & $2 e-126$ \\
\hline 0045 & 11 & S-adenosylmethionine synthetase (Medicago truncatula) & ABO84685 & $1 e-100$ \\
\hline 0047 & II & Ubiquitin-like protein (Pisum sativum) & ABN05665 & $5 e-44$ \\
\hline 0048 & 11 & Major intrinsic protein (Medicago truncatula) & ABE8I405 & $7 e-98$ \\
\hline
\end{tabular}

encoding 2-hydroxyisoflavanone dehydratase, isoflavone 2 '-hydroxylase and isoflavone reductase (Figure 2). Flavonoid $4^{\prime}-O$-methyltransferase was also found in the lupin EST collection (Additional File 2).

In prenylated isoflavone biosynthesis, a prenyl (dimethylallyl pyrophosphate; DMAPP) group is attached to the core isoflavone molecule, catalyzed by a prenyltransferase. DMAPP is synthesized from its allylic precursor isopentenyl pyrophosphate (IPP) through either the cytosolic mevalonate pathway and or the plastidial 2-C-
methyl-D-erythritol-4-phosphate (MEP) pathway [32]. Unigenes encoding enzymes of both the plastidial MEP pathway, including 1-deoxy-D-xylulose-5-phosphate reductoisomerase and 4-hydroxy-3-methylbut-2-enyl diphosphate synthase, and the cytosolic mevalonate pathway (3-hydroxy-3-methylglutaryl-CoA reductase) were present in the white lupin root cDNA library (data not shown). Two unigenes homologous to the UbiA family prenyltransferases were also found and may encode the isoflavone prenyltransferase(s) for prenylated isoflavone synthesis in white lupin (Additional File 2; Figure 2). 


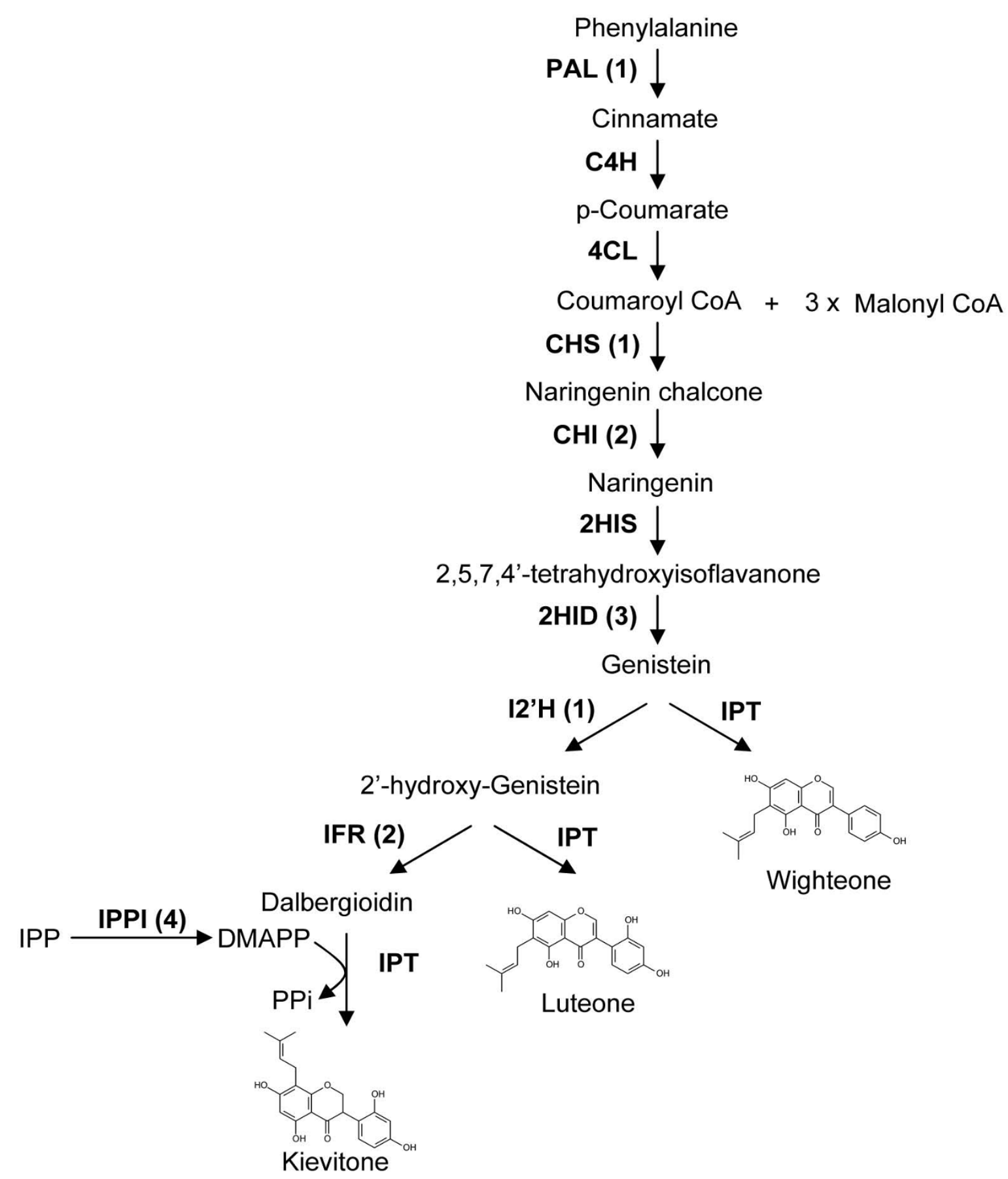

Figure 2

Biosynthetic steps leading to prenylated isoflavonoids in white lupin. Chemical structures of selected prenylated isoflavonoids are shown. Enzymes that catalyze the biochemical reactions are shown, with the corresponding number of identified white lupin root ESTs indicated in parentheses. PAL, L-phenylalanine ammonia-lyase; $C 4 \mathrm{H}$, cinnamate 4-hydroxylase; 4CL, 4coumarate:CoA ligase; $\mathrm{CHS}$, chalcone synthase; $\mathrm{CHI}$, chalcone isomerase; $2 \mathrm{HIS}$, 2-hydroxyisoflavanone synthase; $2 \mathrm{HID}$, 2hydroxyisoflavanone dehydratase; I2'H, isoflavone 2'-hydroxylase; IFR, isoflavone reductase; IPPI, isopentenyl diphosphate/ dimethylallyl diphosphate isomerase; IPT, isoflavone prenyltransferase. 
$\mathrm{ABC}$ transporters have been implicated in transport and root exudation of plant secondary metabolites $[11,33]$. Previous data also suggested that multiple ABC transporters could be involved in transporting a single group of metabolites [33]. Three ABC transporter homologs, including one MRP subfamily transporter, were identified in the white lupin root EST collection (Table 2) and may potentially be involved in secretion of isoflavone metabolites.

\section{Metal uptake, transport and phosphate uptake}

Previous studies have focused primarily on the physiology of (heavy) metal uptake and transport in white lupin, but the process is not well understood at the molecular level. The present study identified 11 unigenes that were homologous to (heavy) metal transport proteins, copper chaperones and metal-transporting P-type ATPase from other plant species, but which had not been reported previously from white lupin (Table 3). Two unigenes showed high similarity to Medicago truncatula ZRT- and IRT-like proteins (ZIP), MtZIP1 and MtZIP4, respectively. MtZIPs were shown to functionally complement yeast metaluptake defective mutants [34]. Specifically, MtZIP1 and MtZIP4 could restore the growth of mutant yeast in Znand Mn-limited media, respectively, suggesting that the two unigenes may encode $\mathrm{Zn}$ and $\mathrm{Mn}$ transporters in white lupin roots. Two unigenes were homologous to soluble copper chaperones that are responsible for intracellular distribution of copper ions [35]. Metal transporting ATPases interact with metallochaperones and function in transmembrane transport of metals. A homolog of metal transporting ATPase, PAA1, was present in the cDNA library. In Arabidopsis, PAA1 interacts with copper chaperones and transports $\mathrm{Cu}$ across the plastid envelope [36]. Six white lupin root unigenes contained heavy metal associated domains, suggesting roles of the encoded proteins in heavy metal transport or detoxification [37].

Malate and citrate secretion to soil is observed from white lupin plants grown under low phosphate. Malate dehydrogenase, 2-oxoglutarate/malate translocator, citrate lyase and citrate synthase are key enzymes for citrate and malate metabolism and unigenes encoding these proteins were found in the cDNA library. These genes have also been implicated in aluminum tolerance [38]. Furthermore, several families of transcription factors, including MYB, WRKY, APETALA2 (AP2) and bHLH, have been implicated in the regulation of plant responses to phosphate starvation [39]. In addition, MYB and bHLH transcription factors are also involved in the regulation of metal uptake and transport [40-42]. Three bHLH, five WRKY, seven MYB and three AP2 transcription factors were represented in the developing white lupin root cDNA library and may function in phosphate and metal ion uptake and transport (Additional File 3).

\section{Characterization of SSR markers}

Microsatellites or simple sequence repeats (SSRs) are tandemly repeated DNA sequences (in most cases 1-6 bases in length) highly abundant throughout prokaryotic and eukaryotic genomes [43]. Microsatellite markers are extremely informative, mostly co-dominant, and show simple Mendelian inheritance over repeated generations. The repeat elements in a motif are usually di-, tri-, tetra- or penta-nucleotides, and the number of blocks for each repeat element can be highly variable even among closely related individuals of the same species.

The white lupin EST collection was examined for SSR sequences by PhpSSRMiner. From the 2,455 unigenes, 82 sequences (3.34\%) exhibited perfect SSRs, with 61 different motifs. The top 10 motifs are summarized in Additional File 4, and represent a diverse set of sequence types. Primer sequences for amplifying the SSR motifs were designed using PhpSSRMiner, which could potentially be used by plant breeders in marker-assisted selection applications (Additional File 5).

\section{A protein reference map of developing white lupin roots}

To provide a more comprehensive understanding of white lupin root biology, we generated a reference map of total proteins extracted from developing roots. One thousand two hundred $\mu \mathrm{g}$ proteins were separated by isoelectric focusing on a nonlinear gradient of $\mathrm{pH} 3$ to 11 according to their isoelectric point, and were subsequently separated in a second dimension on a $12 \%$ SDS-PAGE gel according to their molecular mass (Figure 3). A total of 190 protein spots were selected across the pI and molecular mass

Table 2: White lupin root unigenes that are homologous to ATP binding cassette family transporters.

\begin{tabular}{|c|c|c|c|c|}
\hline Unigene & \# ESTs & BLAST hit & $\begin{array}{c}\mathrm{NCBI} \\
\text { Accession No. }\end{array}$ & $E$ value \\
\hline 1888 & I & $A B C$ transporter homolog (Populus nigra) & BAA945II & $4 e-80$ \\
\hline 1858 & I & $\begin{array}{l}\text { ATMRPI (Arabidopsis thaliana multidrug resistance-associated protein I); xenobiotic-transporting } \\
\text { ATPase }\end{array}$ & NP_174329 & $4 e-30$ \\
\hline 1682 & I & $\mathrm{ABC}-2 ; \mathrm{ABC}$ transporter related (Medicago truncatula) & $A B O 8 \mid 333$ & $3 e-07$ \\
\hline
\end{tabular}


Table 3: White lupin root unigenes that are homologous to metal binding/transport proteins.

\begin{tabular}{|c|c|c|c|c|}
\hline Unigene & \# ESTs & BLAST hit & $\begin{array}{c}\mathrm{NCBI} \\
\text { Accession No. }\end{array}$ & $E$ value \\
\hline 2019 & 1 & Metal transport protein, ZIP4 (Medicago truncatula) & AAR084I4 & $6 e-67$ \\
\hline 1902 & 1 & Metal transport protein, ZIPI (Medicago truncatula) & AAR084I2 & $8 e-60$ \\
\hline 0187 & 3 & Copper chaperone homolog CCH (Glycine max) & AAFI5286 & le-37 \\
\hline 1528 & 1 & Copper chaperone (Populus alba $\times$ Populus tremula var. glandulosa) & AATI 2488 & $3 e-30$ \\
\hline 0570 & 1 & Metal-transporting P-type ATPase (Arabidopsis thaliana) & CAA20565 & $1 \mathrm{e}-10$ \\
\hline 1804 & 1 & $\begin{array}{l}\text { Heavy-metal-associated domain-containing protein/copper chaperone }(\mathrm{CCH}) \text {-related (Arabidopsis } \\
\text { thaliana) }\end{array}$ & NP_I92597 & $4 e-56$ \\
\hline 0413 & 2 & $\begin{array}{l}\text { Heavy-metal-associated domain-containing protein/copper chaperone }(\mathrm{CCH}) \text {-related (Arabidopsis } \\
\text { thaliana) }\end{array}$ & NP_I 97247 & $4 e-53$ \\
\hline 0797 & 1 & Heavy metal transport/detoxification protein (Medicago truncatula) & ABE84676 & $5 e-61$ \\
\hline 0980 & 1 & Heavy metal transport/detoxification protein (Medicago truncatula) & ABE90818 & $6 e-31$ \\
\hline 1141 & 1 & Heavy metal transport/detoxification protein (Medicago truncatula) & ABE90826 & $2 e-27$ \\
\hline 2409 & I & Heavy metal transport/detoxification protein (Medicago truncatula) & ABE93893 & $8 e-25$ \\
\hline
\end{tabular}

range and were excised from the 2 -D gel. The protein spots were digested with trypsin and the eluted peptides subjected to PMF using a MALDI-TOF mass spectrometer. High quality peptide mass spectra were obtained for 170 protein spots.

The automated Mascot search engine http://www.matrix science.com was used to identify protein sequences in the NCBInr database based on mass spectra. Searches against this database did not yield significant matches according to the Mascot protein scores, defined as $-10 * \log (\mathrm{P})$, where $P$ is the probability that the observed match is a random event. The Mascot probability-based scoring system for PMF takes into account the abundance of homologous proteins in the target database and relies on the database size. The NCBInr database contains more than 5 million protein sequences derived from over 5,000 organisms. The overall low protein scores observed are possibly due to the relatively low abundance of white lupin protein homologs in the large NCBInr database. A target database that is small in size, but "enriched" in white lupin protein homologs, was needed to improve the confidence of protein identifications.

A custom legume database was therefore constructed and searched to facilitate the identification of white lupin proteins (Lei et al., unpublished). The legume database contains protein sequences from several leguminous species, namely Medicago sativa, M. truncatula, Lotus japonicus, Gly- cine max, Pisum sativum, Phaseolus vulguris, Lupinus albus and L. luteus. Six-frame translations of the white lupin unigene sequences from the EST analysis were also included in the legume database. Furthermore, tentative contig (TC) sequences of M. truncatula, G. max and L. japonicus were translated into protein sequences and added to the legume database. TCs are assembled from overlapping ESTs, thus containing longer and more useful sequence information than the underlying ESTs. TC sequences have previously been used to enhance protein identification success rate in M. truncatula [20,21]. Out of the 170 analyzed protein spots, 21 could be matched confidently (Mascot protein score $>75$ ) to sequences in the legume database. Fourteen additional protein spots had Mascot protein scores between 50 and 75 , but the majority of peaks in the spectra overlapped with the matched peptides, suggesting a confident match. Peptide information and Mascot protein scores of the 35 identified proteins are provided in Additional File 6. Though in most cases only one protein match was found for each protein spot, two distinct proteins were identified for protein spot 61 (Additional File 6).

The above proteomic analysis provided further insight into biological function and metabolism of developing white lupin roots. Proteins involved in ATP production were present, including triosephosphate isomerase and glyceraldehyde 3-dehydrogenase in glycolysis and NADH dehydrogenase in the mitochondrial respiratory complex. 


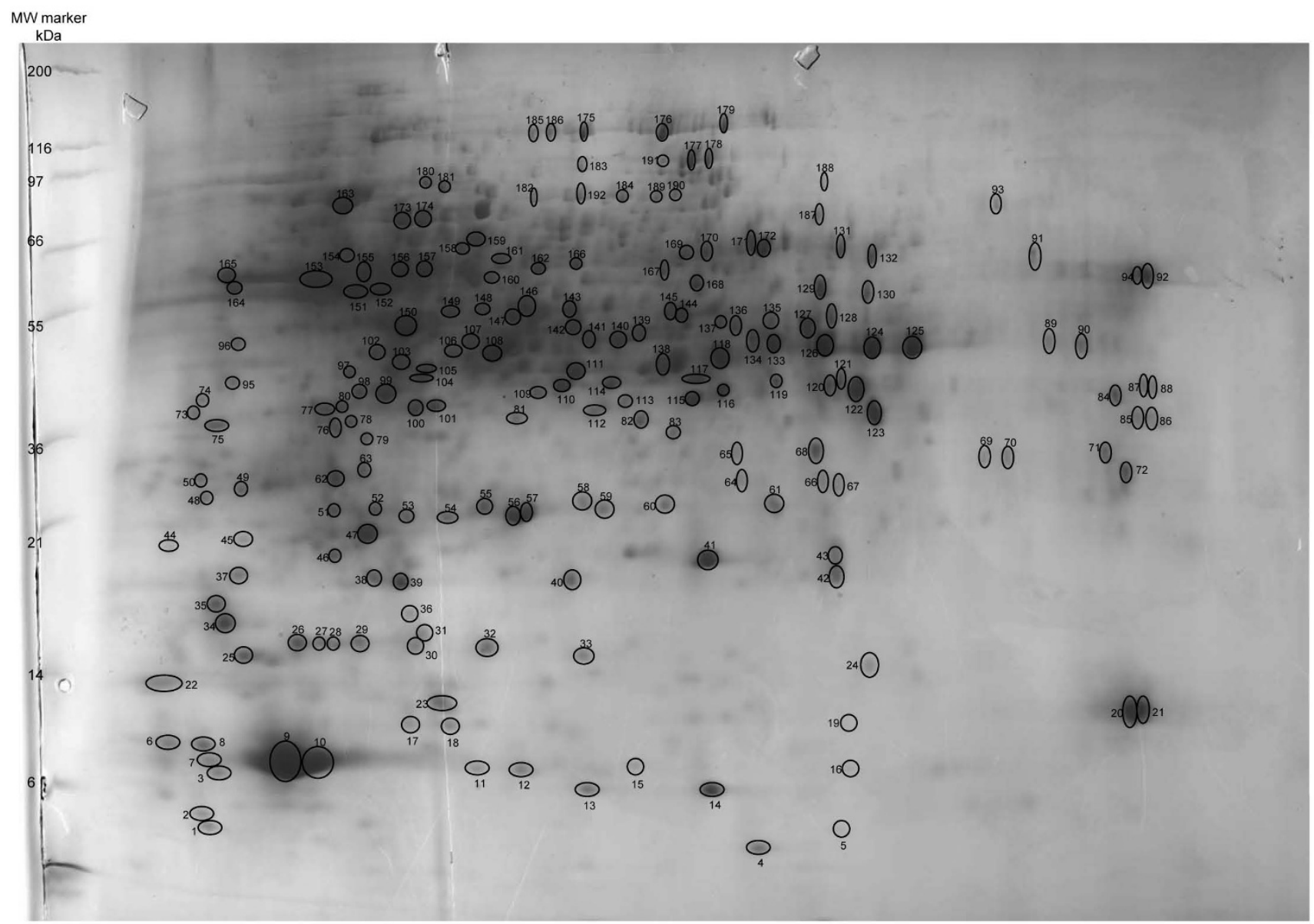

Figure 3

2-D reference map of total proteins extracted from developing white lupin roots. One thousand two hundred $\mu \mathrm{g}$ proteins were separated by IEF ( $\mathrm{pH} 3-\mathrm{II}$ ) and SDS-PAGE (I2\% vertical gel) and stained with Coomassie blue R-250. One hundred and ninety proteins were selected (indicated by numbered spots) across the $\mathrm{Pl}$ and molecular mass range, in-gel digested with trypsin and subjected to MALDI-TOF peptide mass fingerprinting.

Ascorbate peroxidase is a critical component of the reactive oxygen species (ROS) scavenging system. Cytosolic ascorbate peroxidase is essential for plant defense responses [44] and was found in the white lupin root total proteins. Proteins involved in flavonoid, fatty acid and amino acid metabolism were abundant: including chalcone synthase and dihydroflavonol 4-reductase for flavonoid biosynthesis; $\beta$-ketoacyl synthase that adds malonylACP to fatty acids for chain elongation; serine hydroxymethyltransferase that catalyzes the reversible conversion of serine and glycine; and glutamine synthetase that catalyzes the condensation of glutamate and ammonia to form glutamine, a process that assimilates ammonia and is important in nitrogen metabolism.

\section{Membrane proteins from developing white lupin roots}

Membrane proteins are typically underrepresented in 2-D gel analyses using total proteins because of protein precip- itation caused by the hydrophobic domains [45]. A 1-D gel approach was therefore undertaken to identify membrane proteins from developing white lupin roots. Following electrophoresis, the SDS-PAGE gel was cut into sixteen $5 \mathrm{~mm}$ slices (Figure 4). After in-gel trypsin digestion, peptides were extracted from each gel slice, passed through a cation exchange column and three fractions were collected: flow-through, $500 \mathrm{mM}$ and $1 \mathrm{M}$ ammonium acetate eluates, respectively. An aliquot of each fraction was loaded onto a reverse phase HPLC column and analyzed by LC-MS/MS. In contrast to the PMF method for protein identification, LC-MS/MS analysis obtains the protein sequence information by fragmentation of individual peptides. A total of 39 unique proteins were identified by two or more peptides (Table 4).

Mitochondrial and vacuolar ATPases were highly abundant in the membrane fraction (Table 4). ATPases are 
Table 4: List of membrane proteins from developing white lupin roots identified by LC-MS/MS.

\begin{tabular}{|c|c|c|c|c|}
\hline Protein annotation & Score & Protein Mass (Da) & \# Peptides & \%Coverage \\
\hline Adenosine triphosphatase (Phaseolus vulgaris) & 518 & 55310 & 12 & 27.4 \\
\hline Adenine nucleotide translocator (Lupinus albus) & 345 & 42134 & 8 & 23.7 \\
\hline FI ATPase (Pisum sativum) & 310 & 60113 & 7 & 13.9 \\
\hline Adenine nucleotide translocator (Lupinus albus) & 117 & 39769 & 5 & 15.7 \\
\hline AAA ATPase (Medicago truncatula) & 243 & 167308 & 4 & 2.8 \\
\hline ATPase beta subunit (Nicotiana sylvestris) & 188 & 22337 & 4 & 25 \\
\hline Plasma membrane $\mathrm{H}+$ ATPase (Lupinus albus) & 106 & 105034 & 4 & 4.2 \\
\hline Trans-cinnamic acid 4-hydroxylase (Pisum sativum) & 104 & 57023 & 4 & 8.8 \\
\hline 60S ribosomal protein L22-2 (RPL22B) (Arabidopsis thaliana) & 148 & 20969 & 3 & 17.5 \\
\hline Histone H4 (Hyacinthus orientalis) & 106 & 20687 & 3 & 16.7 \\
\hline $\mathrm{H}^{+}$-transporting two-sector ATPase (Medicago truncatula) & 92 & 33840 & 3 & 12.3 \\
\hline DDT; Homeodomain-related (Medicago truncatula) & 40 & 19112 & 3 & 13.8 \\
\hline Hypothetical protein (Medicago truncatula) & 123 & 20972 & 2 & 9.6 \\
\hline PDR-like ABC-transporter (Glycine max) & 112 & 162565 & 2 & 1.3 \\
\hline Heat shock protein Hsp70 (Medicago truncatula) & 111 & 61346 & 2 & 4.3 \\
\hline BiP-isoform D (Glycine max) & 104 & 54230 & 2 & 5.1 \\
\hline 605 ribosomal protein (Medicago sativa) & 95 & 20286 & 2 & 12.8 \\
\hline Mitochondrial phosphate transporter (Glycine max) & 91 & 39765 & 2 & 4.8 \\
\hline 60S ribosomal protein LI2 (Capsicum annuum) & 90 & 22609 & 2 & 13.9 \\
\hline Clathrin heavy chain (Glycine max) & 90 & 193232 & 2 & 1.2 \\
\hline Aquaporin (Lupinus albus) & 84 & 45880 & 2 & 6.8 \\
\hline Putative ATP synthase (Arabidopsis thaliana) & 84 & 22787 & 2 & 9 \\
\hline Clathrin propeller, N-terminal (Medicago truncatula) & 80 & 193039 & 2 & 1.2 \\
\hline Glycoprotein-like protein (Solanum tuberosum) & 79 & 22873 & 2 & 9.4 \\
\hline $\begin{array}{l}\text { Vacuolar ATP synthase catalytic subunit A (Vacuolar proton pump subunit alpha) (Vigna } \\
\text { radiata var. radiate) }\end{array}$ & 77 & 23405 & 2 & 8 \\
\hline $\mathrm{H}+$ transporting ATPase, proton pump (Medicago truncatula) & 76 & 10487| & 2 & 2.6 \\
\hline Ubiquinol-cytochrome $\mathrm{C}$ reductase complex 14 kDa protein, putative (Arabidopsis thaliana) & 72 & 25275 & 2 & 10.2 \\
\hline
\end{tabular}


Table 4: List of membrane proteins from developing white lupin roots identified by LC-MS/MS. (Continued)

\begin{tabular}{|c|c|c|c|c|}
\hline 40S ribosomal protein SI4 (Lupinus luteus) & 71 & 22413 & 2 & 13.2 \\
\hline Orn/DAP/Arg decarboxylase 2; Heat shock protein Hsp70 (Medicago truncatula) & 70 & 22803 & 2 & 11.8 \\
\hline $60 S$ ribosomal protein L23a (Daucus carota) & 64 & 26851 & 2 & 9.6 \\
\hline Ly200 protein (Capsicum annuum) & 61 & $24|7|$ & 2 & 9.1 \\
\hline Ribosomal protein LI3a (Lupinus luteus) & 56 & 23496 & 2 & 11.7 \\
\hline Glycoprotein-like protein (Solanum tuberosum) & 56 & 26610 & 2 & 9.5 \\
\hline Trans-cinnamate 4-monooxygenase $(\mathrm{C} 4 \mathrm{H})$ (Medicago sativa) & 53 & 58243 & 2 & 3.6 \\
\hline Putative ATP synthase subunit (Glycine max) & 51 & 20242 & 2 & 12.3 \\
\hline Translation elongation factor IA-5 (Gossypium hirsutum) & 51 & 64778 & 2 & 3.3 \\
\hline Probable aquaporin PIP-type 7a (Turgor-responsive protein 7a) (Pisum sativum) & 41 & 26029 & 2 & 9.2 \\
\hline Ubiquitin extension protein (Lupinus albus) & 39 & 23489 & 2 & 10.8 \\
\hline Unnamed protein product (Vitis vinifera) & 34 & 23564 & 2 & 6.7 \\
\hline
\end{tabular}

often transmembrane proteins. The dephosphorylation of ATP to ADP releases energy and is coupled to import of metabolites for cellular and enzymatic functions and export of toxins and wastes. Consistent with their representation in the EST dataset, $\mathrm{ABC}$ transporters and aquaporins, which assist in water passage through membranes, were also found in the membrane proteome analysis (Tables 1 and 4 ).

Two characteristic ER-localized proteins were found in the microsomal fraction of developing white lupin roots. The chaperone $\mathrm{BiP}$ is a luminal binding protein in the ER. The molecular weight of this protein in Glycine max is $104 \mathrm{kD}$. Its white lupin homolog was separated on the 1-D gel in the molecular weight range of $70 \mathrm{kD}$ to $103 \mathrm{kD}$ (Figure 4, gel slice 4). Cinnamate 4-hydroxylase $(\mathrm{C} 4 \mathrm{H})$ is a membrane-bound cytochrome P450 enzyme that participates in the early steps of phenylpropanoid pathway metabolism and has been shown to be bound to ER-membranes [46]. Two white lupin root microsomal proteins, homologous to Medicago sativa and Pisum sativum $\mathrm{C} 4 \mathrm{H}$, respectively, migrated around the $50 \mathrm{kD}$ size marker on the 1-D gel (Figure 4, gel slice 7; Table 4). Although the two white lupin $\mathrm{C} 4 \mathrm{H}$ proteins had similar molecular mass, they were eluted at $1 \mathrm{M}$ and $500 \mathrm{mM}$ ammonium acetate, respectively, suggesting that they have different ionic charge properties. Endomembrane and plasmamembrane proteins, such as glycoproteins potentially involved in cell signaling and recognition, ribosomal proteins and heat shock proteins potentially involved in protein synthesis, were also quite abundant in the membrane fraction.

\section{Conclusion}

Using genomic and proteomic approaches, we have identified candidate genes and proteins involved in (heavy) metal binding and transport, and antimicrobial isoflavonoid biosynthesis and transport, in white lupin roots. Further biochemical characterization of the candidate genes is needed to unequivocally delineate their functions in planta. The combined EST and protein datasets from developing white lupin root will not only contribute to our understanding of the response of white lupin to environmental stresses, but will also have broad application in the study of plant nutrient uptake, disease resistance and phytoremediation. Furthermore, our data provide a basis for future comparative studies between developing roots and the cluster roots that are formed under phosphate deficiency. Finally, the EST collection has been mined for SSR markers that will be potentially valuable for marker assisted selection of important agronomic traits in lupin. These markers could also enhance marker density in the white lupin linkage map (developed using amplified fragment length polymorphisms [AFLPs] and candidate genebased markers) [47].

\section{Authors' contributions}

LT carried out the CDNA library and PMF analyses, performed protein extractions, and drafted the manuscript. GJP carried out the 2-D gel and PMF analyses, and performed protein extractions. ZL carried out the LC-MS/MS analysis. NA generated the cDNA library. DX, JH and PZ performed the bioinformatic analyses on the ESTs. BW carried out the 2-D gel analysis. LWS assisted in the pro- 


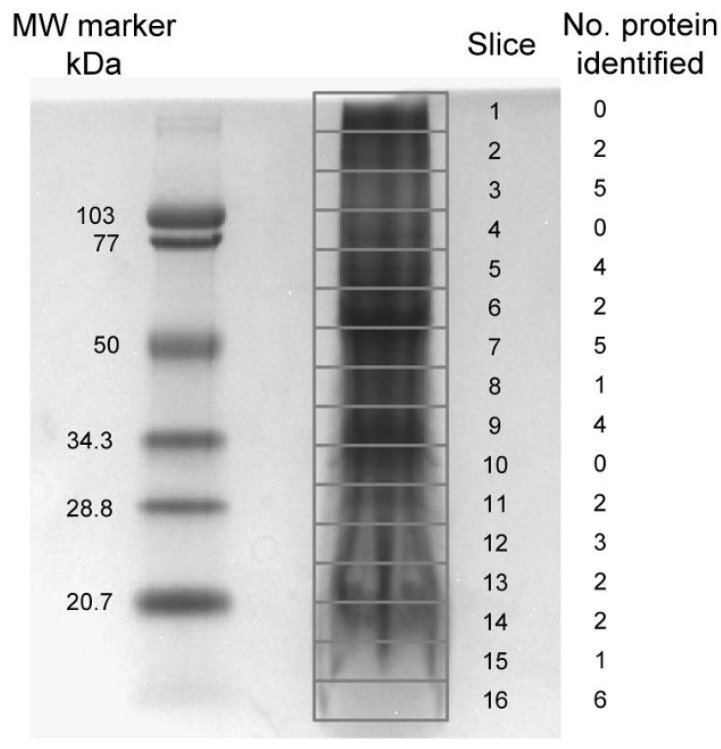

Figure 4

I-D SDS-PAGE gel of developing white lupin root microsomal proteins. One hundred $\mu \mathrm{g}$ microsomal proteins were solubilized in SDS-PAGE sample buffer and separated on a 4-15\% gradient polyacrylamide gel. The protein gel was stained with Coomassie blue R-250. Sixteen $5 \mathrm{~mm}$ slices were excised from the I-D gel as outlined. The gel slices were digested with trypsin and subjected to LC-MS/MS analysis.

tein data analysis. RAD conceived of the study, directed the experimentation, and assisted in the preparation of the manuscript. All authors read and approved the final manuscript.

\section{Additional material}

\section{Additional file 1}

Developing white lupin root unigene BLAST results. BLAST search results of developing white lupin root unigenes against the NCBI database. Click here for file

[http://www.biomedcentral.com/content/supplementary/14712229-9-1-S1.xls]

\section{Additional file 2}

Genes with homology to phenylpropanoid biosynthetic pathway enzymes. Developing white lupin root unigenes that are similar to phenylpropanoid biosynthetic pathway enzymes from other plants based on the deduced amino acid sequences.

Click here for file

[http://www.biomedcentral.com/content/supplementary/14712229-9-1-S2.doc

\section{Additional file 3}

Putative transcription factors in the white lupin root cDNA library. Developing white lupin root unigenes encode putative transcription factors.

Click here for file

[http://www.biomedcentral.com/content/supplementary/14712229-9-1-S3.doc]

\section{Additional file 4}

The top 10 motifs in the SSR markers from the white lupin root cDNA library. The most common and distinguishable SSR motifs identified in the developing white lupin root cDNA library. Only perfect SSR markers with a minimum length of 20 nucleotides were scored.

Click here for file

[http://www.biomedcentral.com/content/supplementary/14712229-9-1-S4.doc]

\section{Additional file 5}

Primer sequences for amplifying white lupin SSR motifs. SSR motifs that were identified from the developing white lupin root ESTs and primer sequences that were designed using PhpSSRMiner for amplification of these white lupin SSRs.

Click here for file

[http://www.biomedcentral.com/content/supplementary/14712229-9-1-S5.xls]

\section{Additional file 6}

Proteins identified in developing white lupin roots by MALDI-TOF mass spectrometry. A summary of white lupin root proteins identified by peptide mass fingerprinting.

Click here for file

[http://www.biomedcentral.com/content/supplementary/14712229-9-1-S6.doc]

\section{Acknowledgements}

We thank David McSweeney for greenhouse assistance and Drs. Maria Monteros and Xiaoqiang Wang for critical reading of the manuscript. This work was supported by the Samuel Roberts Noble Foundation and the National Science Foundation Plant Genome Program Research Award \#DBI-0109732 (for provision of the Applied Biosystems QSTAR instrument).

\section{References}

I. González-Sama A, Lucas MM, de Felipe MR, Pueyo J]: An unusual infection mechanism and nodule morphogenesis in white lupin (Lupinus albus). New Phytol 2004, I 63:37I-380.

2. Reay PF, Waugh C: Mineral-element composition of Lupinus albus and Lupinus angustifolius in relation to manganese accumulation. Plant Soil 1981, 60:435-444.

3. Ximenez-Embun P, Rodriguez-Sanz B, Madrid-Albarran Y, Camara C: Uptake of heavy metals by lupin plants in artificially contam. inated sand: Preliminary results. Int J Environ Anal Chem 2002, 82:805-8।3

4. Page V, Weisskopf L, Feller U: Heavy metals in white lupin: Uptake, root-to-shoot transfer and redistribution within the plant. New Phytol 2006, I $71: 329-341$.

5. Dixon RA: Natural products and disease resistance. Nature 200 I, 4 I I :843-847.

6. Harborne JB, Ingham JL, King L, Payne M: The isopentenyl isoflavone luteone as a pre-infectional antifungal agent in the genus Lupinus. Phytochemistry 1976, I 5: I485- I 487.

7. Barron D, Ibrahim R: Isoprenylated flavonoids - a survey. Phytochemistry 1996, 43:921-982. 
8. Sasaki K, Mito K, Ohara K, Yamamoto H, Yazaki K: Cloning and characterization of naringenin 8-prenyltransferase, a flavonoid-specific prenyltransferase of Sophora flavescens. Plant Physiol 2008, I44: I075-1084.

9. Rea PA: Plant ATP-binding cassette transporters. Annu Rev Plant Biol 2007, 58:347-375.

10. Bartholomew DM, van Dyk DE, Lau SM, O'Keefe DP, Rea PA, Viitanen PV: Alternate energy-dependent pathways for the vacuolar uptake of glucose and glutathione conjugates. Plant Physiol 2002, 130:1562-1572.

II. Goodman CD, Casati P, Walbot V: A multidrug resistance-associated protein involved in anthocyanin transport in Zea mays. Plant Cell 2004, 16:1812-1826.

12. Sugiyama A, Shitan N, Yazaki K: Involvement of a soybean ATP. binding cassette-type transporter in the secretion of genistein, a signal flavonoid in legume-rhizobium symbiosis. Plant Physiol 2007, 146:2000-2008.

13. Erba M, Certel M, Uslu MK: Some chemical properties of white lupin seeds (Lupinus albus L.). Food Chem 2005, 89:34I-345.

14. Liu J, Uhde-Stone C, Li A, Vance C, Allan D: A phosphate transporter with enhanced expression in proteoid roots of white lupin (Lupinus albus L.). Plant Soil 200 I, 237:257-266.

15. Uhde-Stone C, Gilbert G, Johnson JM, Litjens R, Zinn KE, Temple S], Vance C, Allan D: Acclimation of white lupin to phosphorus deficiency involves enhanced expression of genes related to organic acid metabolism. Plant Soil 2003, 248:99-II6.

16. Uhde-Stone C, Liu J, Zinn KE, Allan D, Vance C: Transgenic proteoid roots of white lupin: a vehicle for characterizing and silencing root genes involved in adaptation to $\mathbf{P}$ stress. Plant J 2005, 44:840-853.

17. Uhde-Stone C, Zinn KE, Ramirez-Yáñez M, Li A, Vance C, Allan D: Nylon filter arrays reveal differential gene expression in proteoid roots of white lupin in response to phosphorus deficiency. Plant Physiol 2003, I 3 I: 1064-1079.

18. He J, Dai X, Zhao X: PLAN: A web platform for automating high-throughput BLAST searches and for managing and mining results. BMC Bioinformatics 2007, 8:53.

19. Bradford MM: A rapid and sensitive method for the quantitation of microgram quantities of protein utilizing the principle of protein-dye binding. Anal Biochem 1976, 72:248-254.

20. Watson BS, Asirvatham VS, Wang L, Sumner LW: Mapping the proteome of barrel medic (Medicago truncatula). Plant Physiol 2003, | 31: | | 104- | | 23

21. Lei Z, Elmer AM, Watson BS, Dixon RA, Mendes PJ, Sumner LW: A two-dimensional electrophoresis proteomic reference map and systematic identification of $I 367$ proteins from a cell suspension culture of the model legume Medicago truncatula. Mol Cell Proteomics 2005, 4:1812-1825.

22. Kantety RV, Rota ML, Matthews DE, Sorrells ME: Data mining for simple sequence repeats in expressed sequence tags from barley, maize, rice, sorghum and wheat. Plant Mol Biol 2002, 48:50I-5I0

23. Abajian C: Sputnik. [http://abajian.net/sputnik].

24. Rozen S, Skaletsky H: Primer3 on the WWW for general users and for biologist programmers. In Bioinformatics methods and protocols: methods in molecular biology Edited by: Krawetz S, Misener S. Totowa: Humana Press; 2000:365-386.

25. Kuhn RM, Karolchik D, Zweig AS, Trumbower H, Thomas DJ, Thakkapallayil A, Sugnet CW, Stanke M, Smith KE, Siepel A, Rosenbloom KR, Rhead B, Raney BJ, Pohl A, Pedersen JS, Hsu F, Hinrichs AS, Harte RA, Diekhans M, Clawson H, Bejerano G, Barber GP, Baertsch R, Haussler D, Kent WJ: The UCSC genome browser database: Update 2007. Nucl Acids Res 2007, 35:D668-D673.

26. Ashburner M, Ball CA, Blake JA, Botstein D, Butler H, Cherry JM, Davis AP, Dolinski K, Dwight SS, Eppig JT, Harris MA, Hill DP, IsselTarver L, Kasarskis A, Lewis S, Matese JC, Richardson JE, Ringwald M, Rubin GM, Sherlock G: Gene ontology: Tool for the unification of biology. The Gene Ontology Consortium. Nat Genet 2000, 25:25-29.

27. Rhee SY, Beavis W, Berardini TZ, Chen G, Dixon D, Doyle A, GarciaHernandez M, Huala E, Lander G, Montoya M, Miller N, Mueller LA, Mundodi S, Reiser L, Tacklind J, Weems DC, Wu Y, Xu I, Yoo D Yoon J, Zhang $P$ : The Arabidopsis information resource (TAIR): A model organism database providing a centralized, curated gateway to Arabidopsis biology, research materials and community. Nucl Acids Res 2003, 31:224-228.
28. Berardini T, Mundodi S, Reiser R, Huala E, Garcia-Hernandez M, Zhang P, Mueller L, Yoon J, Doyle A, Lander G, Moseyko N, Yoo D, Xu I, Zoeckler B, Montoya M, Miller N, Weems D, Rhee S: Functional annotation of the Arabidopsis genome using controlled vocabularies. Plant Physiol 2004, I 35: I- I I.

29. Bantignies B, Séguin J, Muzac I, Dédaldéchamp F, Gulick P, Ibrahim R: Direct evidence for ribonucleolytic activity of a PR-I0-like protein from white lupin roots. Plant Mol Biol 2000, 42:87I-88I.

30. Ramírez M, Graham MA, Blanco-López L, Silvente S, Medrano-Soto A, Blair MW, Hernández G, Vance CP, Lara M: Sequencing and analysis of common bean ESTs. Building a foundation for functional genomics. Plant Physiol 2005, 137:1211-1227.

31. Kohler A, Delaruelle C, Martin D, Encelot N, Martin F: The poplar root transcriptome: analysis of 7000 expressed sequence tags. FEBS Lett 2003, 542:37-4

32. Lichtenthaler HK: The I-deoxy-D-xylulose-5-phosphate pathway of isoprenoid biosynthesis in plants. Annu Rev Plant Physiol Plant Mol Biol 1999, 50:47-65.

33. Badri D, Loyola-Vargas V, Broeckling $C$, De-la-Peña C, Jasinski M, Santelia D, Martinoia E, Sumner L, Banta L, Stermitz F, Vivanco J: Altered profile of secondary metabolites in the root exudates of Arabidopsis ATP-binding cassette transporter mutants. Plant Physiol 2008, 146:762-771.

34. López-Millán AF, Ellis DR, Grusak MA: Identification and characterization of several new members of the ZIP family of metal ion transporters in Medicago truncatula. Plant Mol Biol 2004, 54:583-596

35. O'Halloran TV, Culotta VC: Metallochaperones, an intracellular shuttle service for metal ions. I Biol Chem 2000, 275:25057-25060.

36. Abdel-Ghany SE, Müller-Moulé P, Niyogi KK, Pilon M, Shikanai T: Two P-type ATPases are required for copper delivery in Arabidopsis thaliana chloroplasts. Plant Cell 2005, I7:I233-I25I.

37. Bateman A, Coin L, Durbin R, Finn RD, Hollich V, Griffiths-Jones S, Khanna A, Marshall M, Moxon S, Sonnhammer EL, Studholme DJ, Yeats C, Eddy SR: The Pfam protein families database. Nucl Acids Res 2004, 32:DI38-DI4I.

38. Tesfaye M, Temple SJ, Allan DL, Vance CP, Samac DA: Overexpression of malate dehydrogenase in transgenic alfalfa enhances organic acid synthesis and confers tolerance to aluminum. Plant Physiol 200I, 1 27: 1836-1844.

39. Tesfaye M, Liu J, Allan DL, Vance CP: Genomic and genetic control of phosphate stress in legumes. Plant Physiol 2007, 144:594-603.

40. Ling H, Bauer P, Bereczky Z, Keller B, Ganal M: The tomato fer gene encoding a bHLH protein controls iron-uptake responses in roots. Proc Natl Acad Sci USA 2002, 99:13938-13943.

4I. Yuan Y, Zhang J, Wang D, Ling H: AtbHLH29 of Arabidopsis thaliana is a functional ortholog of tomato fer involved in controlling iron acquisition in strategy I plants. Cell Res 2005, I5:613-62I.

42. Chen $Y, W u X$, Ling $H$, Yang $W$ : Transgenic expression of DwMYB2 impairs iron transport from root to shoot in Arabidopsis thaliana. Cell Res 2006, 16:830-840.

43. Varshney R, Graner A, Sorrells M: Genic microsatellite markers in plants: Features and applications. Trends Biotech 2005, 23:48-55

44. Davletova S, Rizhsky L, Liang H, Shengqiang Z, Oliver D, Coutu J, Shulaev V, Schlauch K, Mittler R: Cytosolic ascorbate peroxidase I is a central component of the reactive oxygen gene network of Arabidopsis. Plant Cell 2005, 17:268-28I.

45. Herbert B: Advances in protein solubilisation for two-dimensional electrophoresis. Electrophoresis 1999, 20:660-663.

46. Ro DK, Mah N, Ellis BE, Douglas Cl: Functional characterization and subcellular localization of poplar (Populus trichocarpa $\times$ Populus deltoides) cinnamate 4-hydroxylase. Plant Physiol 200I, 126:317-329.

47. Phan HTT, Ellwood SR, Adhikari K, Nelson MN, Oliver RP: The first genetic and comparative map of white lupin (Lupinus albus L.): identification of QTLs for anthracnose resistance and flowering time, and a locus for alkaloid content. DNA Res 2007, 14:59-70. 